\title{
Timing is everything: an audit of process and outcomes from a pilot advanced scope physiotherapy model of care for women with pelvic floor conditions
}

This article was published in the following Dove Medical Press journal:

Clinical Audit

\author{
Kate Goode' \\ Tara Beaumont ${ }^{1}$ \\ Saravana Kumar ${ }^{2}$ \\ 'Department of Physiotherapy, \\ Women's and Children's Hospital, \\ Adelaide, SA, Australia; ${ }^{2} \mathrm{School}$ of \\ Health Sciences, Division of Health \\ Sciences, University of South \\ Australia, Adelaide, SA, Australia
}

\begin{abstract}
Introduction: Incontinence and pelvic organ prolapse (POP) commonly affect many people for whom physiotherapy may be an important, front-line management strategy. However, traditional referral pathways in the tertiary health care system limit or delay access to this management option resulting in poor outcomes.
\end{abstract}

Objective: The aim of this pilot study was to determine the impact of an advanced scope of practice physiotherapy model of care for women referred with incontinence and/or POP symptoms compared to traditional referral pathways in a tertiary hospital in Australia.

Methods: A prospective audit was conducted with consecutive sampling of those triaged into the physiotherapy-led clinic during the trial period. A database was created to record patient demographic information, key dates in the patient pathway, and the clinical outcome measures obtained. Results: Forty-one women were assessed in the physiotherapy-led clinic during the trial period October 2015-March 2016. The results indicate improved access to care (time between referral to first consult during the trial was 27.3 days, compared with 169.6 days first consult using the traditional referral pathway), improved adherence to conservative management ( $96 \%$ attending their individual consultation compared to 55\%) and positive patient satisfaction.

Conclusion: This pilot study demonstrated that an advanced scope physiotherapy-led model of care such as the Gynecology Physiotherapy Assessment Service can result in improved access to care while positively impacting experiences of women with incontinence and/or POP symptoms. Keywords: advanced scope, physiotherapy, incontinence, pelvic organ prolapse, conservative management, physical therapy

\section{Introduction}

Pelvic floor muscle training (PFMT) supervised by a physiotherapist has been shown to be a highly effective treatment option for a number of pelvic floor conditions, such as stress urinary incontinence and pelvic organ prolapse (POP). ${ }^{1,2}$ Recommendations based on high-level and high-quality research evidence support the role of PFMT as first-line treatment for stress, urge and mixed urinary incontinence and POP, effectively mandating that this conservative management option should be considered in the clinical care pathway. ${ }^{3}$ The role of PFMT is crucial as the incidence of POP has been estimated to be as high as $50 \%$ in parous woman when assessed by vaginal examination, with bothersome symptoms reported by approximately 1 in 10 women aged between 45 and 86 years. ${ }^{4,5}$ Urinary incontinence affects up to $37 \%$ and fecal incontinence up to $13 \%$ of Australian women. ${ }^{6}$ It is estimated that $11 \%$ of women will need surgery for
Correspondence: Saravana Kumar Health Sciences, University of South Australia, GPO Box 247I, Adelaide, SA 5001 , Australia

Tel +6I 883022085

Fax +61883022766

Email saravana.kumar@unisa.edu.au 
prolapse or incontinence at least once in their lifetime by the age of 80 years and almost $30 \%$ will require repeat surgery for symptom recurrence. ${ }^{7,8}$ Patients at tertiary centers may wait several months for a consultation with a medical specialist, following which they may proceed to surgical management prior to trialing conservative management options. ${ }^{9,10}$ Untreated urinary incontinence can have a significant impact on a woman's well-being and health-related quality of life, as can bothersome prolapse symptoms. ${ }^{11,12}$

As conservative management has been shown to be effective in the management of pelvic floor conditions, an advanced scope of practice model of care was proposed at a tertiary hospital in Adelaide, Australia (Women's and Children's Hospital [WCH]). In an advanced scope of practice, a health professional can be considered as an expert working within the scope of established practice due to increased clinical knowledge and skills, reasoning, critical thinking and experience. Advanced scope of practice in physiotherapy has been successfully trialed in a number of fields, particularly in orthopedic and emergency department settings, and has more recently seen success in the continence and women's health. ${ }^{13-15}$ This model of care involves the physiotherapist performing a role, which is currently recognized within their scope of practice but has traditionally been performed by other professions such as medical practitioners. ${ }^{16}$ Preliminary research undertaken at WCH demonstrated lengthy delays between local health care provider referral and access to physiotherapy. ${ }^{9}$ This research also highlighted that many patients who would have been appropriate to trial conservative physiotherapy management in the first instance did not follow this care pathway. ${ }^{9}$

\section{Development of Gynecology Physiotherapy Assessment Service (GPAS)}

Therefore, the GPAS, an advanced scope physiotherapy-led initiative, was implemented in October 2015. The development of the GPAS was underpinned by an extensive consultation process that was undertaken in June 2015 involving key stakeholders of the pilot program, primarily from the Gynecology Department and Physiotherapy Department. Firsthand accounts were also gathered from physiotherapists around Australia with experience in implementing and evaluating similar models of advanced scope of practice. Executive approval for the pilot program was granted in September 2015 and the GPAS clinic commenced in October 2015. The weekly GPAS clinic was set up to run alongside a gynecology consultant clinic to ensure that adequate access to a senior gynecology registrar and staff specialist for clinical opinions and supervision were available as required. The co-location in the Women's Outpatient Department facilitated open communication lines between the key stakeholders. Figure 1 provides an overview of the GPAS pathway.

The purpose of GPAS was to improve access to conservative management for women referred to the Gynecology Department, who suffered from conditions that were likely to respond positively to conservative physiotherapy-led management as a stand-alone treatment, or attain additional benefits when combined with medical and/or surgical treatment options in the future. ${ }^{3,17}$ The GPAS model was primarily designed to enhance the patient pathway through the tertiary health care system, ensuring faster access to initial consultation with a health professional. Although the role of advanced scope of practice in physiotherapy in continence and women's health has been trialed across numerous clinical settings, there is limited research on this topic. Therefore, the aim of this pilot study was to determine the impact of an advanced scope of practice physiotherapy model of care for women referred with incontinence and/or POP symptoms compared to traditional referral pathways in a tertiary hospital in Australia.

\section{Methods \\ Design}

A prospective audit was conducted on patients who were referred to the GPAS clinic with pelvic floor conditions from October 1, 2015, to March 24, 2016. Given the pilot nature of this research, no formal sample size calculations were undertaken. Consecutive sampling was used to select all patients who presented to the GPAS clinic during the period of the audit.

\section{Participants}

Eligibility criteria were defined to include patients with urgency and/or incontinence (urinary and/or anal symptoms), POP (grades I-III) or mixed presentations, all of whom were concurrently triaged as low priority "P3" by the gynecology team (as determined by the information available from the referral at the time of triage). Patients were excluded if they had any red flags outlined on the referral although these were generally triaged as a "P1" or "P2" due to the need for immediate or accelerated access to care and were thus already excluded from the pilot program.

\section{Procedures}

A number of staff and patient resources were developed to support and guide service delivery in the GPAS clinic. A key resource was the GPAS information sheet, which was 


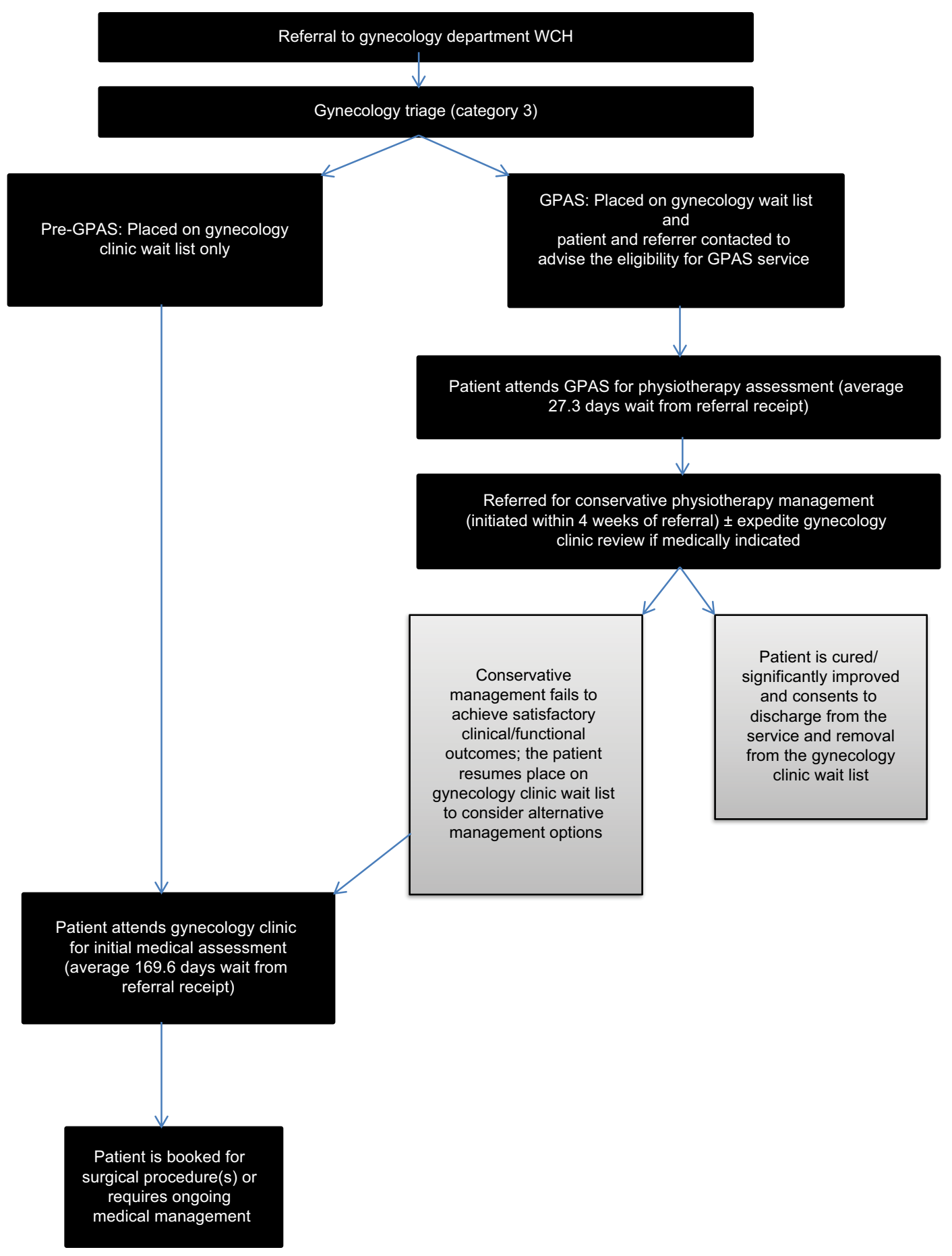

Figure I GPAS pathway.

Abbreviations: GPAS, Gynecology Physiotherapy Assessment Service; WCH, Women's and Children's Hospital.

created for patients triaged into the GPAS pathway to outline the advantages of this model of care and importance of early physiotherapy intervention for conditions such as POP and incontinence. It was felt that it was important to inform patients not only that their first point of contact would be with a physiotherapist rather than a medical practitioner but also that the opportunity to provide an early explanation of the benefits of conservative physiotherapy management may contribute to a more positive reception to the clinic. A letter was also sent to the referring medical caregiver explaining the fast tracking of the patient for physiotherapy assessment in GPAS. Both the letter to the referring medical caregiver 
and the GPAS information sheet provided to the patient outlined that the referral had been received and placed on the gynecology waiting list (per the existing pathway), but in addition to this, the patient had been identified as eligible for the fast tracking of an assessment within the GPAS pathway. The patient maintained their place on the gynecology waiting list, regardless of their participation in the GPAS pathway. A referral pathway flow diagram was developed for the administrative team (and for the benefit of all key stakeholders) to ensure that the GP referrals moved efficiently through the triaging system while ensuring that the original remained on the gynecology wait list and the appropriate GPAS booking letters and factsheets were generated.

A database was created to record patients' demographic information for those accessing the GPAS pathway, map the patient pathway from the date of medical caregiver referral to discharge from physiotherapy and/or gynecology and record the clinical outcome measures obtained for each patient. The time difference (days) between referral from medical caregiver to GPAS and medical caregiver referral to physiotherapy input (via GPAS) as well as attendance rates at physiotherapy and ongoing adherence rates were collected and compared to data from the "pre-GPAS" audit. ${ }^{9}$ A concurrent retrospective audit was completed to identify the existing referral pathway to physiotherapy services for women who would have met GPAS inclusion criteria prior to its implementation. The period for the retrospective audit was from January 2015 to June 2015, and this was used as comparison data. ${ }^{9}$

Ethics approval was granted by the Women's and Children's Health Network Human Research Ethics Committee (WCHN HREC) in July 2015 to enable data collection for analysis of the GPAS pathway (audit 798A) and patient satisfaction for the GPAS cohort (audit 796A). Patients were informed of the GPAS pathway by the invitation letter and by attending their allocated appointment at GPAS, and they became a consenting participant in this initiative.

\section{Outcomes}

In order to capture the impact on patient outcomes from the GPAS clinic, following permission from its developers, the validated, self-administered version of the Australian Pelvic Floor Questionnaire (APFQ) was produced in a patient friendly format and sent to patients prior to attendance at the GPAS clinic. ${ }^{18}$ Despite best efforts to collect these data, due to complexities associated with data collection in a complex tertiary care environment and heterogeneity in the data collection process, these data were not included in further analysis. Throughout the 6-month pilot program an anonymous satisfaction survey, designed specifically to analyze the patient's experience in GPAS, was also utilized (Supplementary material). The survey instrument contained questions in two categories - the first category contained seven questions about the patient's experience with the physiotherapist specifically and the second category contained three questions about the patient's overall experience with the clinic. The physiotherapist-centric questions had a focus on the physiotherapist's interaction with the patient (processes of care), whereas the clinical experience included questions that had a focus on structural aspects of care (such as appointment time, punctuality etc). These questions were rated on a fivepoint Likert scale from excellent to poor or strongly agree to strongly disagree depending on the statement. The survey also included a "does not apply" option. There was also an open-ended question for patients to provide any additional comments and feedback. The survey instrument, which was locally developed and already in use at another clinic, was completed by the patient at the end of their appointment and submitted via a survey box to maintain anonymity.

\section{Results \\ Overview of participants}

During the period October 1, 2015, to March 24, 2016, 21 GPAS clinics ran with a total of 52 patients identified as appropriate for the GPAS pathway by the triaging member of the gynecology team. Of the eligible "P3" patients offered an appointment, 41 women (79\%) attended, all of whom were appropriate for referral to the Physiotherapy Department to commence conservative management through the existing pathway. Figure 2 provides an overview of patient selection and participation. The average age of the patients who attended GPAS was 45.3 years, the youngest was 20 years old and the oldest was 77 years old. Eleven women referred to GPAS did not attend, and attempts were made to contact these women. Of those able to be contacted, the reasons for non-attendance varied from inconvenient clinic time to disinterest in conservative management options. The main problem outlined on the medical caregiver referral correlated with at least some of the findings at GPAS clinics on all occasions. However, secondary diagnoses or additional issues were identified in 25 patients. This mostly related to urinary or fecal urgency \pm incontinence and the reporting of dyspareunia when questioned regarding sexual function. Fifty out of $52(96 \%)$ patients referred to GPAS clinics by the gynecology team were appropriate based on the inclusion criteria. Only two instances required redirection as one patient had already been referred to physiotherapy and the 


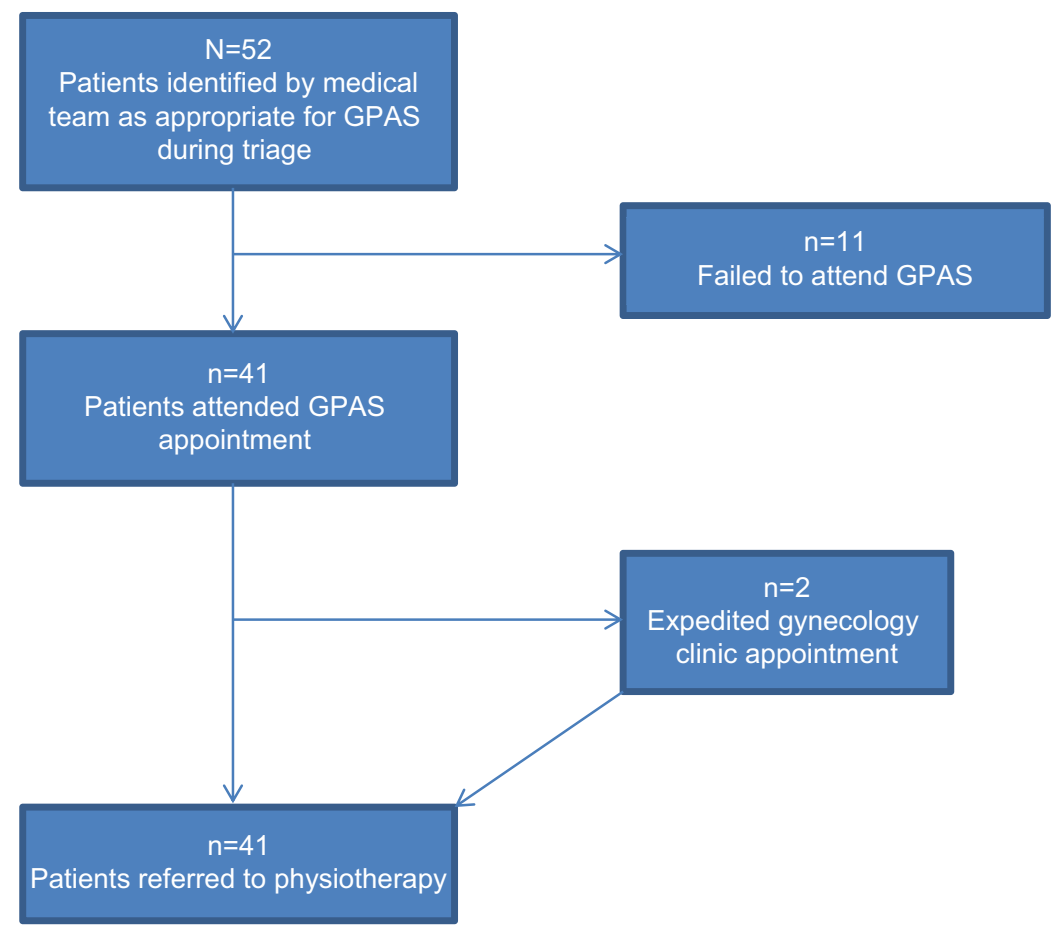

Figure 2 Overview of patient selection and participation in the GPAS. Abbreviation: GPAS, Gynecology Physiotherapy Assessment Service.

other required specialist medical input for another medical condition. Further investigations at the initial consult were ordered via the medical team on two occasions (urodynamic studies and pelvic + renal ultrasound), and two patients were "fast-tracked" through the gynecology wait list because they were deemed to be of higher priority for medical review following GPAS assessment.

\section{Access to care}

The average length of time between medical caregiver referral to the first offered GPAS clinic appointment during the pilot program for those with complete data sets (two patients excluded due to poor referral receipt documentation) was 27.3 days (range 8-62 days). This was in stark comparison to 169.6 days (range 49-351 days) for medical caregiver referral to gynecology clinic appointment during the pre-GPAS audit period. ${ }^{9}$ Feedback from patients indicated that they valued receiving a timely review for their condition and were relieved at the improved access to care. From a clinical point of view, the ability to complete timely screening of patients in GPAS resulted in the "fast-tracking" of two patients who may have been at the risk of deterioration and poor outcomes and had waited until their gynecology appointment was offered as per the pre-GPAS pathway. Of the women who attended the appointment $(n=41)$ and with complete data sets $(n=40)$, the average length of time between medical caregiver referral and attendance at the GPAS clinic was 72.9 days (range 41-121 days). Some women canceled or did not attend their originally scheduled session, and their actual first contact occurred later as a result. When the actual dates of first contact were evaluated, the average length of time between medical caregiver referral and contact in the Physiotherapy Department was 84.6 days (range $42-172$ days).

\section{Adherence to conservative management}

Of the women referred to physiotherapy, 35 out of 41 were appropriate for the group pelvic floor class (PFC), which was the first point of contact with physiotherapy. The six patients did not participate in the PFC due to a number of reasons including existing access to physiotherapy treatment at the health service $(n=1)$ and those from non-English-speaking backgrounds requiring interpreting services $(n=5$, where group education was not appropriate). Of the 35 women who were triaged to attend the PFC, 24 attended these classes (68.6\%). Of these 24 patients who attended PFC, 23 (96\%) continued with physiotherapy care in the form of ongoing individual consultation. This finding highlights that women referred through GPAS were likely to adhere to the conservative management and persisted with their individual appointments after that initial contact. This is likely due 
to better awareness of the physiotherapy pathway and the benefits of conservative management created through the GPAS consultation.

\section{Attendance at conservative management sessions}

Attendance at the PFC was $68.6 \%$, which was very similar to that found in the pre-GPAS audit $(71.4 \%) .{ }^{9}$ From a clinical point of view, an important positive finding was the number of women persevering with the conservative pathway by attending their individual appointment following the PFC, which increased from $55 \%$ in the pre-GPAS cohort to $96 \%$ (23 of 24 possible attendees) in the GPAS cohort (Figure 3 ). Of the women who were not appropriate for the preliminary group session (PFC), five of the six women attended their first individual appointment. The likely reasons for the improved attendance include increased awareness of the benefits of the proposed care pathway from an early stage starting with the information sheet sent with the appointment letter, a more comprehensive explanation of management options being provided by the physiotherapist at the GPAS consult and finally having this message reinforced at the PFC. Another benefit of the GPAS pathway is the ability to perform digital vaginal examination and pelvic floor assessment at the time of the GPAS appointment.

\section{Patient satisfaction}

Evaluation of patient satisfaction with GPAS consisted of an anonymous survey, which was administered at the end of the episode of care. The survey was completed by 31 patients (76\% response rate) with overwhelming positive responses. With regard to the processes of care, all 31 patients (100\%) rated willingness of the physiotherapist to listen, the amount of time spent with the physiotherapist and the ability of the physiotherapist to explain things in a way that could be understood, as “excellent/very good". Similarly, 97\% of the patients rated the time taken to answer questions, the thoroughness of the examination, the advice provided and the way they were involved in decision making about their care as "excellent/very good". With regard to the structural aspects of care, where the questions focused on the clinic, $90 \%$ of the patients "strongly agreed/agreed" that their appointment time suited them, 74\% "strongly agreed/agreed" that their appointment ran on time and $97 \%$ "strongly agreed/agreed" that they were made to feel comfortable in the clinic. The free text question provided patients with an opportunity to provide any additional qualitative comments and approximately $50 \%(15 / 31)$ provided comments. Similar to the quantitative findings, qualitative data indicated overwhelming positive responses. A number of comments reflected the patient's interaction with the physiotherapist "[Physiotherapist] was great - felt comfortable - very empathetic - good listener - clear communicator". Comments also centered on the service and new knowledge relating to management options for their condition such as "A fantastic service! Very reassuring in terms of the potential to avoid surgery and very informative with respect to what is now known about pelvic floor exercises".

\section{Discussion}

The aim of this pilot study was to determine the impact of an advanced scope of practice physiotherapy model of care for women referred with incontinence and/or POP symptoms compared to traditional referral pathways in a tertiary hospital in Australia. The findings from this GPAS pilot program highlight improved patient pathway for women referred with incontinence and/or POP symptoms, with improved timely screening of patients and significantly faster access to conservative physiotherapy management. Access to conservative management for eligible women rose from $50 \%$ to $100 \%$,

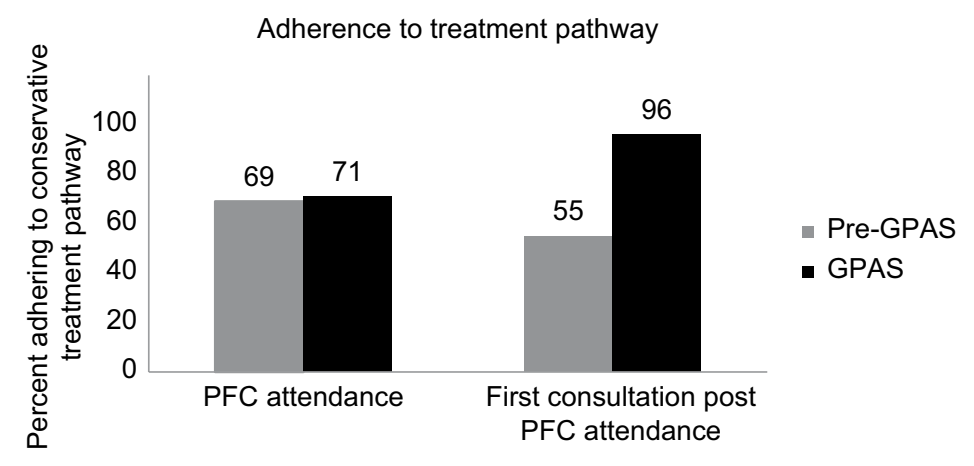

Figure 3 Participant adherence to treatment pathway pre and during GPAS.

Abbreviations: GPAS, Gynecology Physiotherapy Assessment Service; PFC, pelvic floor class. 
which means these women were more likely to proceed to a favorable outcome whether they do go on to require further surgical and/or medical input or not. Furthermore, the GPAS pathway appeared to improve attendance and reduce the attrition, which is commonly observed in clinical practice as patients may perceive rehabilitation as slower and more arduous, when compared to the perceived "quick fix" of surgery. From a patient perspective, the positive clinical findings were complemented with overwhelming positive patient satisfaction about GPAS. Given the project's success in improving patient access and adherence, if it were to be implemented on an ongoing basis, consideration of funding frameworks would be necessary to ensure that timely access to services is sustainable. This research contributes to the growing body of evidence that advanced physiotherapy-led initiatives can have positive impacts on health care. For example, in a systematic review of the literature, Desmeules et $\mathrm{al}^{13}$ demonstrated that there was some evidence to indicate that physiotherapists working in advanced physiotherapy models of care in musculoskeletal disorders provide equal or better than usual care in comparison to physicians in terms of diagnostic accuracy, treatment effectiveness, use of health care resources, economic costs and patient satisfaction. Similarly, de Gruchy et $\mathrm{al}^{19}$ identified that physiotherapists acting as primary practitioners in emergency departments were more time efficient when compared to physicians. Within South Australia, where this pilot program was conducted, similar positive findings were reported by Beard et $\mathrm{al}^{20}$ who demonstrated that physiotherapist-led spinal assessment telehealth clinic reduced travel for patients and clinicians, provided timely access to care and afforded professional development opportunities for staff who often work in isolation in rural and remote regions. Therefore, while advanced physiotherapy-led initiatives may not be appropriate in every instance, it could be considered as an alternative option in targeted contexts.

The implementation of the GPAS pathway also resulted in other benefits. For example, there were several occasions where the physiotherapist within GPAS initiated further investigations or recommendations regarding relevant medical treatments through the patient's general practitioner in conjunction with the referral for conservative physiotherapy management. This meant if and when a medical specialist consultation was required to determine the eligibility of a patient for surgery, all relevant information was readily available to make a timely and well-informed decision at the initial consultation (thereby avoiding further delay or inappropriately selecting surgery as the best treatment option). The importance of selecting the right treatment for the right patient has been widely acknowledged in the incontinence literature. ${ }^{21-23}$ Lack of careful consideration on appropriate patient selection for surgery may lead to complications and poor outcomes, ${ }^{24}$ which have resulted in the development of evidence-informed algorithms for best practice management. ${ }^{25}$

The GPAS pathway not only has the potential to reduce the number of review appointments required before conversion to surgery but also ensured that the patients who were accessing this management option were the most appropriate candidates with a greater chance of a successful clinical outcome because of their pre-operative physiotherapy input. ${ }^{17}$ Existing research also highlights that up to $25 \%$ of women actually complete a counterproductive maneuver, such as straining, when provided with only verbal cues on how to contract the pelvic floor with this issue more commonly observed in women with POP. ${ }^{26,27}$ Thus, the ability to comprehensively assess pelvic floor issues, provide feedback and achieve effective technique earlier in the pathway is likely to be beneficial. These positive findings of the GPAS pilot program are also supported by a number of studies on the benefits of physiotherapy for urinary incontinence. Neumann et $\mathrm{al}^{1}$ demonstrated that specialized ambulatory physiotherapy was a low-cost, low-risk and effective treatment, which should be offered as a first-line treatment for stress urinary incontinence. Similar positive findings were also reported by Balmforth et $\mathrm{al}^{28}$ and Opara et $\mathrm{al}^{29}$ highlighting the potential role for physiotherapy-led initiative for women with urinary incontinence and/or POP symptoms.

Although there were positive outcomes from the GPAS pilot program, as with any research, there were limitations too. First, as patients on the GPAS pathway remained on the gynecology wait list, there were occasions where they were offered a gynecology appointment before they had completed the recommended course of conservative management. This issue was exacerbated during the trial period as the wait for entry to the PFC doubled due to an influx of patients generated from the onset of the GPAS. Although at times a gynecology review was indeed required (eg, consideration of a pessary as an adjunct conservative treatment option), in other instances patients were only part way through their conservative management when their gynecology appointment became available. Second, this pilot program was undertaken within one tertiary hospital in South Australia and was developed and championed by local clinicians who had completed post-graduate training in the field and experience in managing women with urinary incontinence and/or POP symptoms. Therefore, these issues need to be considered 
when generalizing these findings and if this model of care is to be replicated at other tertiary health settings. It should also be noted that although the tool used to evaluate patient satisfaction was developed specifically for this initiative, it did not undergo validity testing. Finally, given that this research was undertaken in naturalistic settings (in a busy and complex tertiary hospital), despite the researchers' best efforts some critical data could not be captured (eg, APFQ). Nevertheless, this research reports on what occurs at the frontline of clinical practice and is an accurate representation of complexities associated with research in the practice setting.

\section{Implication for clinical practice and future research}

With increasing focus on quality and safety in health care, it is important to ensure that health services are underpinned by best practice principles. The findings from this pilot program have demonstrated that the GPAS, an advanced scope physiotherapy-led initiative, can result in positive impacts for women with urinary incontinence and/or POP symptoms. In addition to organizational benefits, this model of care is also patient-centered as it provides access to timely care, has a focus on self-management and reduces the potential for unnecessary interventions. Although these positive findings are encouraging, given the pilot nature of this program and the fact much of the literature on advanced scope physiotherapy is emerging and focused on one-off initiatives, future research could consider large-scale, long-term studies, which also have a focus on aspects such as cost-effectiveness.

\section{Conclusion}

This pilot study demonstrated that an advanced scope physiotherapy-led GPAS can result in improved access to care while positively impacting experiences of women with incontinence and/or POP symptoms.

\section{Acknowledgment}

The authors would like to acknowledge all the patients and staff at the Physiotherapy Department, Women's and Children's Hospital, Adelaide.

\section{Author contributions}

$\mathrm{KG}$ and $\mathrm{TB}$ conceptualized and collected the relevant data. $\mathrm{KG}$, TB and SK collaborated during the analysis, reporting and development of the manuscript in its current form. All authors contributed toward data analysis, drafting and critically revising the paper, gave final approval of the version to be published, and agreed to be accountable for all aspects of the work.

\section{Disclosure}

The authors report no conflicts of interest in this work.

\section{References}

1. Neumann PB, Grimmer KA, Grant RE, Gill VA. Physiotherapy for female stress urinary incontinence: a multicentre observational study. Aust N Z J Obstet Gynaecol. 2005;45(3):226-232.

2. Hagen S, Stark D, Glazener C, et al. Individualised pelvic floor muscle training in women with pelvic organ prolapse (POPPY): a multicentre randomised controlled trial. The Lancet. 2014;383(9919):796-806.

3. Moore K, Dumoulin C, Bradley C. Committee 12: Adult Conservative Management. In: Abrams P, Cardozo L, Khoury S, Wein A, editors. Incontinence: Proceedings of the 5th International Consultation on Incontinence, Paris, France, Feb 2012. Plymouth: Plymbridge Distributors, Health Publication Ltd; 2012.

4. Barber MD, Maher C. Epidemiology and outcome assessment of pelvic organ prolapse. Int Urogynecol J. 2013;24(11):1783-1790.

5. Slieker-Ten Hove MCP, Pool-Goudzwaard AL, Eijkemans MJC, Steegers-Theunissen RPM, Burger CW, Vierhout ME. Symptomatic pelvic organ prolapse and possible risk factors in a general population. Am J Obstet Gynecol. 2009;200(2):184.e1-18184.

6. Australian Institute of Health and Welfare. Australian incontinence data analysis and development; 2006. Available from: http://www.aihw.gov. au/WorkArea/DownloadAsset.aspx?id=6442455813. Accessed July 21, 2015.

7. Fialkow MF, Newton KM, Lentz GM, Weiss NS. Lifetime risk of surgical management for pelvic organ prolapse or urinary incontinence. Int Urogynecol J. 2008;19(3):437-440.

8. Olsen A, Smith V, Bergstrom J, Colling J, Clark A. Epidemiology of surgically managed pelvic organ prolapse and urinary incontinence. Obstet Gynecol. 1997;89(4):501-506.

9. Beaumont T, Goode K. Identifying the pathway to conservative pelvic floor physiotherapy in a tertiary public hospital in Australia: a retrospective audit. Internet J Allied Health Sci Pract. 2017;15(2).

10. Slack A, Hill A, Jackson S. Is there a role for a specialist physiotherapist in the multi-disciplinary management of women with stress incontinence referred from primary care to a specialist continence clinic? J Obstet Gynaecol. 2008;28(4):410-412.

11. Kwon BE, Kim GY, Son YJ, Roh YS, You MA. Quality of life of women with urinary incontinence: a systematic literature review. Int Neurourol J. 2010;14(3):133-138.

12. Svihrova V, Svihra J, Luptak J, Swift S, Digesu GA. Disability-adjusted life years (DALYs) in general population with pelvic organ prolapse: a study based on the prolapse quality-of-life questionnaire (P-QOL). Eur J Obstet Gynecol Reprod Biol. 2014;182:22-26.

13. Desmeules F, Roy JS, MacDermid JC, Champagne F, Hinse O, Woodhouse LJ. Advanced practice physiotherapy in patients with musculoskeletal disorders: a systematic review. BMC Musculoskelet Disord. 2012;13(1): 107 .

14. Williams M. Streamlining care times. InMotion Magazine. Australian Physiotherapy Association; 2016. November: 60-61. Available from: http://www.printgraphics.net.au/myfiles/InMotion_November_2016/ files/assets/basic-html/page-1.html. Accessed December 16, 2016.

15. Continence Foundation of Australia. Research and innovation in the incontinence world - physiotherapy - a stitch in time. Bridge Magazine. 2017;11(1):8-9.

16. Australian Physiotherapy Association. Australian Physiotherapy Association Position Statement: Scope of Practice; 2009. Available from: https://www.physiotherapy.asn.au/DocumentsFolder/Advocacy_Position_Scope_of_Practice_2009.pdf. Accessed November 24, 2016. 
17. Jarvis SK, Hallam TK, Lujic S, Abbott JA, Vancaillie TG. Peri-operative physiotherapy improves outcomes for women undergoing incontinence and or prolapse surgery: results of a randomised controlled trial. Aust N Z J Obstet Gynaecol. 2005;45(4):300-303.

18. Baessler K, O’Neill SM, Maher CF, Battistutta D. A validated selfadministered female pelvic floor questionnaire. Int Urogynecol J. 2010;21(2):163-172.

19. de Gruchy A, Granger C, Gorelik A. Physical therapists as primary practitioners in the emergency department: Six-month prospective practice analysis. Phys Ther. 2015;95(9):1207-1216.

20. Beard M, Orlando JF, Kumar S. Overcoming the tyranny of distance: an audit of process and outcomes from a pilot telehealth spinal assessment clinic. J Telemed Telecare. 2017;23(8):733-739.

21. Syan R, Brucker BM. Guideline of guidelines: urinary incontinence BJU Int. 2016;117(1):20-33.

22. Hoedl M, Schoberer D, Halfens RJ, Lohrmann C. Adaptation of evidence-based guideline recommendations to address urinary incontinence in nursing home residents according to the ADAPTE-process. J Clin Nurs. 2018;27(15-16):2974-2983.

23. Slade SC, Hay-Smith J, Mastwyk S, Morris ME, Frawley H. Strategies to assist uptake of pelvic floor muscle training for people with urinary incontinence: a clinician viewpoint. Neurourol Urodyn. 2018;37(8):2658-2668.
24. Bacsu C, Zimmern P. Complications of treatment of urinary incontinence and pelvic organ prolapse. Revista Médica Clínica Las Condes. 2013;24(2):229-237.

25. Cundiff GW, Quinlan DJ, van Rensburg JA, Slack M. Foundation for an evidence-informed algorithm for treating pelvic floor mesh complications: a review. BJOG. 2018;125(8):1026-1037.

26. Bump RC, Hurt WG, Fantl JA, Wyman JF. Assessment of Kegel pelvic muscle exercise performance after brief verbal instruction. Am J Obstet Gynecol. 1991;165(2):322-329.

27. Henderson JW, Wang S, Egger MJ, Masters M, Nygaard I. Can women correctly contract their pelvic floor muscles without formal instruction? Female Pelvic Med Reconstr Surg. 2013;19(1):8-12.

28. Balmforth JR, Mantle J, Bidmead J, Cardozo L. A prospective observational trial of pelvic floor muscle training for female stress urinary incontinence. BJU Int. 2006;98(4):811-817.

29. Opara JA, Socha T, Poświata A. Pelvic floor muscle exercise as the best stress urinary incontinence prevention method in women practising competitive sport. Physiotherapy. 2013;21(2):57-63. 


\title{
Supplementary material
}

\author{
Women's and Children's Health Network
}

Women's and Children's Hospital

Gynecology Physiotherapy Assessment Service - Evaluation Form

Dear patient,

Physiotherapy staff involved in the Gynecology Physiotherapy Assessment Service aim to provide you with a comfortable, convenient and satisfying clinic experience, along with optimum health care. We would like to know how you feel about your clinic visit today and would appreciate any further comments/feedback you might have. Participation in this survey is voluntary and your responses are confidential. Your feedback and comments will help us evaluate our service and ensure that we are meeting the needs of our patients. The survey may be returned via mail to Women's Physiotherapy or placed in the survey box located in the Women's Outpatient Department where your clinic appointment is held. If you have any further questions or concerns about your visit today, please call the Women's Physiotherapy Department on (08) 81617579 to discuss.

This form has been approved for use by the Women's and Children's Health Network Human Resources Ethics Committee (WCHN HREC), July 2015. Please contact the WCHN HREC if you have any concerns about this form on (08) 81616390.

Thank you!

Please rate the following:

\begin{tabular}{|c|c|c|c|c|c|c|}
\hline & Excellent & Very good & Good & Fair & Poor & $\begin{array}{l}\text { Does not } \\
\text { apply }\end{array}$ \\
\hline \multicolumn{7}{|l|}{ Your visit with the physiotherapist } \\
\hline \multicolumn{7}{|c|}{ Willingness to listen to you } \\
\hline \multicolumn{7}{|l|}{ Taking time to answer questions } \\
\hline \multicolumn{7}{|l|}{ Amount of time spent with you } \\
\hline \multicolumn{7}{|c|}{ Explaining things in a way you could understand } \\
\hline \multicolumn{7}{|c|}{ The thoroughness of the examination } \\
\hline \multicolumn{7}{|c|}{ Advice given to you on ways to stay healthy } \\
\hline \multicolumn{7}{|c|}{$\begin{array}{l}\text { Including you in decision making about your } \\
\text { treatment and/or follow-up plan }\end{array}$} \\
\hline & $\begin{array}{l}\text { Strongly } \\
\text { agree }\end{array}$ & Agree & Neutral & Disagree & $\begin{array}{l}\text { Strongly } \\
\text { disagree }\end{array}$ & $\begin{array}{l}\text { Does not } \\
\text { apply }\end{array}$ \\
\hline \multicolumn{7}{|l|}{ Overall clinic experience } \\
\hline \multicolumn{7}{|l|}{ Clinic appointment time suited me } \\
\hline \multicolumn{7}{|c|}{ Appointments ran to time } \\
\hline I was made to feel comfortable & & & & & & \\
\hline
\end{tabular}

Any further comments/feedback:

Figure SI Women's and Children's Health Network. Women's and Children's Hospital. Gynecology Physiotherapy Assessment Service - Evaluation Form.

Clinical Audit

Publish your work in this journal

Clinical Audit is an international, peer-reviewed, open access journal focusing on the processes and outcomes of clinical audit in any area of healthcare. All aspects of patient care are addressed within the journal and practitioners from all disciplines are invited to submit their work. Areas covered include: Publication of audits; How an audit has changed practice;

Submit your manuscript here: https://www.dovepress.com/clinical-audit-journal

\section{Dovepress}

Practical tips on how to do audits and to avoid pitfalls; How audits have changed patient care; Calls and justifications for new audits. The manuscript management system is completely online and includes a very quick and fair peer-review system, which is all easy to use. Visit http://www.dovepress. $\mathrm{com} /$ testimonials.php to read real quotes from published authors. 